\title{
Construction engineering management culture shift: Is the lowest tender offer dead?
}

C The Author (s) 2017. Published by Higher Education Press. This is an open access article under the CC BY license (http:// creativecommons.org/licenses/by/4.0)

\begin{abstract}
The procurement of public construction projects must walk a fine line between the corruption of state officials and collusion of contractors. The method of awarding projects to the lowest responsible tenderer was originally implemented to guard against corruption of state officials. However, an investigation of the construction industry in the Canadian province of Quebec showed that lowest-tender-offer procurement gave rise to collusion of companies tendering for the contracts. Alternatively, bestvalue procurement has been used for decades, but here problems arise owing to the necessity of subjective judging of measures other than price to compare bids, giving rise to time- and money-consuming protests. The paper proposes a compelling argument that the construction engineering management (CEM) culture should refocus its efforts on enhancing project cost certainty rather than merely searching for means to design a project in a manner that produces the lowest initial cost, and awards the construction to the lowest tender offer that focuses on cost savings during the project development and delivery process. The difference in the two approaches is subtle but extremely important. To make the transition, the engineering management tools must be advanced to the next level. This means that all project control tools for managing cost, schedule, and technical scope must be transformed from working in the deterministic mode to the stochastic mode, thus making the probability of completing the project
\end{abstract}

Received January 11, 2017; accepted March 3, 2017

Eric SCHEEPBOUWER ( $₫)$

Civil and Natural Resources Engineering, University of Canterbury, Christchurch, New Zealand

E-mail: eric.scheepbouwer@canterbury.ac.nz

Douglas D. GRANSBERG

Civil, Construction and Environmental Engineering, Iowa State University, Ames, IA 50011, USA

Carla Lopez del PUERTO

Construction Engineering and Management, University of Puerto Rico, Mayaguez, PR 00681-9000, USA within or below its official budget the primary decision criterion. To do so, CEMs must accept that there is a benefit in paying more for an alternative that increases cost certainty for the entire project. The authors of this paper hope that it will provide the grist for a more general dialog across all industry sectors where engineering management is practiced.

Keywords cost certainty, lowest responsible bid, best value, public procurement, construction engineering management culture

\section{Introduction}

In 2011, Quebec's Justice, France Charbonneau, and Auditor General, Renaud Lachance, were commissioned to investigate allegations of corruption in the Canadian province's construction industry. The allegations implicated politicians, public works officials, labor unions, industry design professionals, construction contractors, and organized crime syndicates (CBC News, 2015). Transportation projects awarded and administered by the Ministry of Transportation Quebec were the commission's focus. With the Charbonneau Commission named, the investigation continued for over four years, heard testimony from nearly 300 witnesses, and produced a 1700-page report containing 60 recommendations for the Quebec provincial government to protect whistleblowers, reform political contribution rules, and revise public works procurement law (Girard, 2016). The commission's report contains the following finding, which encapsulates the motivation for writing this article: "The Commission noted that in order to win a bid [tender], a bidder will reduce his profit margin to increase its chance of winning the bid. However, the Commission noted that the pressure created by such a system (lowest bid [tender offer] wins) incites contractors to devise schemes to recover their discounted profits, for example, claiming for extras [contract change 
orders], whether justified or not, reducing the quality of work carried out, or bribing the project supervisor on the worksite. In the longer terms, bidders may be tempted to develop a whole system of collusion, designed initially to minimize their losses and then, in the longer term, to guarantee stable and sometimes highly lucrative profit margins." (Charbonneau and Lachance, 2015).

The upshot is that the Commission asserted that the price tension in a lowest-tender-offer award system actually facilitated corruption in the design, construction, and engineering management industries instead of shielding against it. It is easy to rationalize the above finding as merely applicable to the Province of Quebec, but to do so is to ignore the more universal public procurement context in which the corruption occurred and which the commissioners found to be contributing factors to both the breadth and depth of the wrongdoing (Curry, 2016). The following four aspects covered in the report apply to all public works procurement systems regardless of nationality (Girard, 2016):

(1) Slavish devotion to lowest-tender-offer award for all construction projects;

(2) Policies focused on cost savings alone;

(3) Loss of internal public agency expertise that leads to increased outsourcing of traditional agency oversight tasks and degrades the ability to determine the reasonableness of project costs;

(4) Creating an environment that makes collusion easy.

Hence, the remainder of this paper will place the above four global implications of the Charbonneau report findings for the construction engineering management (CEM) industry in the context of contemporary project delivery methods using relational rather than transactional contracts. The paper's objective is to initiate a dialog on the following question for construction engineering managers across the globe: Should the long-term objective of current construction project development and delivery procurement strategy be minimizing project cost or maximizing project cost certainty?

In order to reach this objective, a brief historic overview will be given regarding tender award procedures. In particular, the low tender offer (LTO) and the best value procurement (BV) will be briefly highlighted. The paper will then describe project cost certainty and how this principle compares to lowest initial cost. A case study will be used to further illustrate this. Then, the conclusions will be given in the final section.

\section{Tender award procedures}

"About 150 years ago, our forefathers bestowed the competitive bidding concept on us in order to curb corruption, inefficiency, and mismanagement by government officials" (Harp, 1991). At this writing, the reader can add another 15 years to Harp's 150 years, and the transportation sector still awards the majority of its projects to the "lowest responsive and responsible tender offer" (Tran et al., 2016). Most statutory definitions for competitive bidding procurement systems revolve around the following definition:

Low Tender Offer Award Procurement-A procurement process where the contract is awarded to the lowest responsive and/or esponsible tender offeror. (Tran et al., 2016).

The terms responsive and responsible speak to the apparent low tender offer being technically correct per the instructions to tenderers (signed, dated, unambiguous, etc.) and the apparent low tenderer demonstrating that it is competent to perform the work in accordance with the contract terms such as the ability to furnish the requisite bonds and possessing the necessary personnel and equipment (Kraft et al., 2014). In most cases, the LTO process is linear, starting with the client completing a project's detailed design using either in-house or consultant design resources and marrying the design drawings with its standard specifications to form the contract construction documents. These are then combined with agency general and special provisions and subsequently advertised using what is commonly called an invitation for tender offers. Sealed offers are received and publically opened at a specified date and time. The apparent low offer is determined based on a check for responsiveness. Shortly thereafter, the contractor with the lowest responsive tender offer submits the required documentation and is awarded the contract. If a losing competitor believes that some irregularity in the procurement is present, it has the right to file a protest of award, but according to $\mathrm{Yu}$ and Wang (2012), in a "price dominated" LTO procurement system, a successful protest is difficult since the award metric, lowest price, is purely objective.

One advantage of LTO procurement is that it seems to make it easy to demonstrate value for money (VfM) to the nontechnical members of the client's upper management. The use of other award methods requires the client's technical staff to both educate and placate its upper management when it recommends selection of a contractor that is not the lowest offeror (Yuan et al., 2009). However, in agreement with the findings Charbonneau and Lachance (2015), Scott et al. (2006) stated that the award of a contract to a supplier based on lowest tender price alone could be false economy if there is a subsequent default, late deliveries, or other unsatisfactory performance resulting in additional contractual or administrative costs.

"Price is important, but it has become an increasing burden on considering the other necessary product requirements such as timeliness, durability, and quality" (Harp, 1991). Procurement at the lowest price does not necessarily require awarding to the lowest offer. Much research has been conducted regarding the impact on cost, schedule, and quality in the adversarial environment induced by LTO awards. In most cases, researchers have 
found benefits attributable to moving to some form of best value (BV) award system for typical transportation projects (Ellis et al., 1991; Songer et al., 1994; Crowley and Hancher, 1995; Gransberg and Ellicott, 1997; Molenaar and Gransberg, 2001; Higbee, 2004; Federal Highway Administration (FHWA), 2006; Scott et al., 2006; Blanchard, 2007; Scheepbouwer and Humphries, 2011; West et al., 2012; Rueda-Benavides and Gransberg, 2014; Tran et al., 2016). NCHRP Report 561 (Scott et al. 2006) synthesized the BV concepts found in US state and federal statutes. They developed the following definition for "best value award" after identifying 15 different definitions in state procurement statutes alone.

"Best Value Procurement-A procurement process where price and other key factors are considered in the evaluation and selection process to minimize impacts and enhance the long-term performance and value of construction." (Scott et al., 2006).

BV awards are made based on something other than lowest initial cost alone. Bamberger and Stark (2008) posit that BV selections "judge the comparative value of tender offers" and "seek to choose the provider offering the best combination of performance, qualifications, and price." In seeking enhanced value, public owners are turning more often to selections that are not tied inflexibly to price. A possibility lies in relational contracting methods such as alliancing, where the price is set via collaboration with preselected consultant(s) and contractors (Botha and Scheepbouwer, 2015). The literature is rife with examples of how this encourages innovation, minimizes life cycle costs, accelerates schedules, and contractor performance (Gransberg and Ellicott, 1997; Higbee, 2004; Federal Highway Administration, 2006; Scott et al., 2006; Blanchard, 2007; Tran et al., 2016).

At the very least, a synthesis of the previously cited research leads to a consensus that a BV award does not increase ultimate cost, extend construction schedules, or degrade the final constructed quality. One study found that, "On average, the managers of design-build [one specific form of BV] projects surveyed in the study estimated that design-build project delivery reduced the overall duration of their projects by 14 percent, reduced the total cost of the projects by 3 percent, and maintained the same level of quality as compared to design-bid-build project delivery" (Federal Highway Administration, 2006). The same conclusion was reached a decade later by Minchin and Chini (2016) in a study of Florida Department of Transportation (DOT) projects. They used data from approximately $1500 \mathrm{LTO}$ and $900 \mathrm{BV}$ procurement procedures and found that "all [alternative project delivery] methods provided time savings and added quality, [thus] cost savings was the main consideration in [the study's] performance evaluations."

Yet, despite more than 25 years of mounting empirical evidence supporting BV awards, public transportation agencies continue to perpetuate the LTO procurement culture as a result of both statutory mandates and political opposition to BV awards by industry (Minchin and Chini, 2016). The use of BV awards regardless of the composition of the rubric used to select the winner necessarily forces the justification of the incremental benefits gained from qualitative factors against the incremental increase in capital costs (Van de Rijt and Santema, 2012). In BV judging, "comparative value" becomes unavoidably subjective. Therefore, using selections involving subjective evaluations increases the burden on public sector owners to maintain a fair and open process of selection (Bamberger and Stark, 2008).

The salient issue then becomes one of how a public client can incorporate elements that may be perceived as subjective into the contract award process without provoking award protests that may delay construction start and consume time, funding, and personnel resources defending the protest (Shane et al., 2006). The only argument that truly remains for opposing BV awards is the same as it was 165 years ago: Preventing corruption within the agencies that make the construction project award decisions. This was an argument that may have been debunked by the Charbonneau Commission's finding that "the legislation, regulation and consistency of practices [of the LTO process] of a number of public authorities, has over the years, facilitated collusion strategies."

\section{Value for money by maximizing cost certainty}

As the Charbonneau findings suggest, focusing on awarding projects to the lowest bidder and creating procurement policies that focus on cost savings alone can facilitate corruption. The next question is: how can a public client demonstrate VfM in a manner that can be effectively understood by its nontechnical masters in a budget-constrained environment?

Again, while the BV literature clearly demonstrates its ability to achieve a BV project's critical success factors, the explanations become increasingly arcane, making the communication of VfM increasingly hazy, and worse, more difficult to convincingly justify to the politicians that authorize the funding, the taxpayers, and the media. Therefore, it becomes incumbent upon the client's technical and project management staff to find a simple, eloquent message that can be easily communicated and validated by project performance measures. The US Federal Highway Administration (FHWA) did this in 2010 when it changed the longstanding "better, faster, cheaper" cliché to "better, faster, smarter" (Mendez, 2010), releasing US state DOTs from having to designate the cheapest solution for a highway construction project in order to obtain federal funding (West et al., 2012). The FHWA also picked up a second slogan for highway construction projects: "Get in, get out, stay out," which 
clearly indicates a preference for the speedy completion of highway construction in a manner that gives increased weight to the project schedule and a design that maximizes highway service life. Both factors are typically in conflict with getting the project at the lowest possible cost (Tran et al., 2016). However, taken on a whole-of-life basis, both factors are in harmony with a paradigm shift in the CEM project delivery culture to maximize cost certainty.

\subsection{Preconstruction phase engineering management}

Desiring to finish a construction project under budget and ahead of schedule, while logical, in fact unintentionally induces a bias to deliberately overestimate both cost and time (Odeck, 2004). Moreover, the overarching objective in public projects is never to ask for more money or more time from the entity that provides the funding (Arditi et al., 1985). Thus, the issue becomes one of making planning, programming, and design decisions that promote both cost and time certainty. In many countries, the prevailing practice is to award preconstruction service contracts such as environmental permitting, design, surveying, and subsurface investigations on an LTO basis (Bubshait et al., 1998). This merely extends the focus on cost savings backward from construction to the project scope definition and detailing process, thus minimizing the effort that can be applied in the design and other processes based on a budget constrained by competitive pricing. Unfortunately, the LTO approach for consultant services fails to recognize that the preconstruction period is where the ultimate quality of the constructed product is defined (Hunter and Gransberg, 2014). As in all things related to construction projects, the final quality is directly related to the quality of the effort applied to the preconstruction tasks (Lopez del Puerto et al., 2016).

A commonly used approach for setting the preconstruction services (PCS) budget is to use a programming-level estimate based on the probable construction cost multiplied by a fixed percentage often found in the client's project development policy documents (Craigie et al., 2016). There are a number of problems with this approach. First, the cliché "you get what you pay for" is applicable when an inaccurate PCS cost estimate turns into a design quality issue because the client's PCS consultants are forced to correlate the level of design refinement with the available PCS budget. Additionally, Crosset and Hines (2007) found that "construction cost overruns often indicate a failure to take into account site-specific factors in the project's design phase." The preconstruction phase is where the engineering manager oversees the technical definition of the project's scope and quantifies the result, including the site-specific factors that affect the final technical design product.

The issue of using a programming-level construction estimate to set the PCS budget is also one of the quality of the construction cost estimate itself. By definition, early estimates are made during project scope definition and as such cannot be considered as accurate (Alavi and Tavares, 2009). As project definition becomes more complete, these estimates tend to grow as the amount of design detail increases. They are also subject to the phenomenon called "scope creep" (Crosset and Hines, 2007). For the purposes of this article, scope creep is defined as the gradual, unrecognized addition of minor improvements to a project's scope of work, whose cumulative effect is to cause project cost growth during design. This definition assumes that the initial estimate is reasonably accurate. Failing to recognize scope requirements in early construction cost estimates is not scope creep; rather, it is an estimating error. The impact of an error of this nature is compounded by using the erroneous number to generate the PCS cost budget using a fixed percentage. In other words, the error causes the unintentional underfunding of the planning and design activities necessary to fully define the final scope of work. According to a study of one public agency's program, "final construction costs were $46 \%$ higher than anticipated at the time of programming" (Alavi and Tavares, 2009).

Gransberg et al. (2014) investigated the need to accurately estimate PCS costs, and found that in most cases PCS estimating accuracy was not considered important. The researchers summed up the issue in the words of one respondent:

"If $4 \%$ of the estimated construction cost is the preconstruction budget, then overrunning it by $10 \%$ is $0.4 \%$ which is a tiny number. So why waste time collecting, processing, and maintaining a preconstruction database when the overall impact of improved estimates and budgets results in a trivial savings?" (Gransberg et al., 2014)

In other words, why care if the PCS budget is off because the outcome is a small amount? This pragmatic analysis ignores the facts that effectively belie the argument. First, while preconstruction budgets are expressed in monetary units, the actual unit of effort is the billable hour for the client's consultants. For example, if a hypothetical fixed-percentage PCS budget equates to 20,000 hours of preconstruction planning, design, and administration effort and is off by $10 \%$, the impact of the error equates to 2000 hours. Since there are 2080 working hours in the typical year, the error equates to nearly one person-year of additional effort. Given the typical cost for consulting engineer time with associated labor burden and benefits, the cost savings bias will equate to something over 100,000 USD. Worse, the consultant that performs the preconstruction activities lacks 2000 hours of billable work effort in its contract. Thus, failing to provide a sufficient budget for completing the project's construction documents is going to result in the consultant needing to either rush to complete its work or reduce the overall amount of time spent on the checking the quality of the final product. While it may be argued that this is not completely true for 
PCS documents developed by in-house planning and design assets, the impact shifts appreciably when the client chooses to outsource a majority of the preconstruction effort (Hunter and Gransberg, 2014). The focus on LTO awards and policies that are oriented on saving costs are the first two of the Charbonneu Commission's findings. The impact of outsourcing PCS activities takes this paper's analysis forward to the Commission's third and fourth findings.

\subsection{Internal public agency expertise}

The shift of oversight responsibilities from the public client to consultants creates potential ethical issues for the consultant. First, consultants often provide professional engineering services to nongovernmental clients in the design and construction industry. Thus, the potential for an engineering firm to have a conflict of interest when one client decides to pursue a project advertised by the same firm's public agency client is heightened (Szeliga, 2005). Second, many public agencies are required by local statute to prequalify design consultants on the basis of past experience and demonstrated technical competence (Hoke, 2012). Thus, to be competitive, a consulting firm must make its public client happy on each and every contract. When one of the preconstruction services is to complete a given LTO project's construction cost estimate, a bias is unintentionally created to inflate the construction estimate to make sure that when the tender offers are opened they do not exceed the engineer's estimate and reflect poorly on the consultants' professional competence, potentially diminishing their competitiveness for future work. If one extends the insidious impact of inflated engineers' construction estimates over a period of decades, one arrives at point where the historical database used to populate the estimate becomes inflated itself, further exacerbating this issue. Couple this with an inexperienced public engineer administering the consultants' contracts, and the environment in which unreasonable tender offers must be identified becomes altered to the point where it is murky if not virtually impossible to detect bid rigging.

The last issue involving the combination of outsourced consulting contracts administered by inexperienced public personnel could include blatant wrongdoing by the consultant by joining the competing contractors in a collusion scheme. If a given project's "official" estimate is compared with the data in a historical database, which has been unintentionally inflated incrementally over a period of years, the ability to detect collusion by an inexperienced public official is greatly handicapped-A finding of the Charbonneau Commission. The fact that the detailed pricing information in the database is publically available on the Internet makes it easier to "calibrate" rigged tender offers to appear to be consistent with past tenders, making the detection of collusion even more difficult. Add a consultant that is criminally benefitting from a bid-rigging scheme, and one literally has the perfect environment in which to hatch nearly undetectable collusion. This is reinforced by the LTO award metric where the members of the scheme can easily control the outcomes of each tender since there is no influence on the award decision other than the lowest number that fits within the budget established by the engineer's estimate itself. The Charbonneau commission's recommendation to use BV awards instead of LTO is founded on the rationale described in this paragraph.

Last, a cursory search of US criminal cases that involved bid rigging, collusion, bribery, and corruption was conducted to determine the current magnitude of the problem in the US case law. The search turned up over 100 potential cases during the period 1981 to 2016 . This period was selected because it was the timeframe when US public agencies began experimenting with BV project delivery, starting with the federal military departments in early 1981 (Beard et al., 2001). This information is provided to demonstrate that collusion persists to the present, and the fact that $90 \%$ of all US public construction projects continue to be delivered using LTO award methods (Gransberg and Molenaar, 2008) indicates that the environment for wrongdoing will be perpetuated. Every case involved rigging the bids on LTO procurements. Some cases involved only a group of contractors and, at times, design consultants representing public agencies. Others involved corruption by public officials who either solicited or accepted bribes. This leads one to infer that many of the Charbonneau findings regarding the ease with which bids can be rigged in a system, where not only are all the numbers published and publicly available but where the winning number can easily be predicted, indeed applies to US agency procurement processes. The same inference is probably applicable outside North America as well.

\subsection{Cost certainty}

Research has shown that construction project cost certainty is enhanced when the client "invests" in the PCS phase, solving technical problems on the drawing board rather than pushing them out to the field where their impact is multiplied when they are realized by the construction contractor (Carr and Beyor, 2005). In traditional LTO project delivery, deficient design quality leads to increased construction cost because the client warrants the quality of the construction documents (Hunter and Gransberg, 2014). Design errors, omissions, and quantity inaccuracies discovered after award of the construction contract must be paid for by contract modifications, which usually increase the final cost of the project (Beemer, 2005). Research completed by Morgen (1986) and Kirby et al. (1988) found that design deficiencies were the primary driver for construction contract changes, and that " $56 \%$ of all modifications are aimed at correcting design deficiencies." Another study by Burati et al. (1992) found that changes resulting from design errors identified after the 
construction contract is awarded accounted for $79 \%$ of all change-order costs for an average of $9.5 \%$ of the total project cost.

Carr and Beyor (2005) reported that design fees have lagged construction inflation for the past three decades. Underfunding project design contracts results in a conundrum where "the high-quality professional services rightfully expected by the public will become increasingly difficult [to attain] if the erosion in fees continues unabated into the future" (Carr and Beyor, 2005). Pricing pressure leads engineers to a point where they must provide the necessary level of design with diminished resources, and this may induce a bias toward minimizing design analyses and cross-checks to maintain project profitability, which would result in the decreased quality of construction documents (Bubshait et al., 1998; Girard, 2016). Janacek (2006) neatly summarizes the problem by stating, "Don't try to squeeze that extra quarter point from their [design] fee. For every dollar you spend up front on design and planning you will save 10 to 20 fold down the line."

More recently, a 2007 study of US DOTs found that only $18 \%$ of projects over 5.0 million USD in the five-year sample were completed within their original award amounts (Crosset and Hines, 2007). The researchers summarized their findings in the following manner:

"In a world of uncertainty when the first shovel of dirt is moved, some surprises are inevitable. The clear ability of some DOTs to outperform others suggests that success factors for limiting surprises or at least limiting their impact on cost and schedule may include fostering accountability for cost and schedule, monitoring causes of problems to identify common culprits, creating incentives for staff and contractors to do better, and strengthening connections between pre-construction and construction work phases. Keeping construction onschedule and on-budget enables [clients] to deliver more projects faster. Avoiding cost overruns in construction means doing good work in preconstruction. Each of the strong performers emphasizes the value of good coordination between the construction and pre-construction phases of project delivery" (Crosset and Hines, 2007).

The research findings cited above infer that cost certainty is not only low when the project development process starts, but that it also fails to improve before the award of the construction contract owing to client failure to properly invest in the preconstruction budget. The previous comment from a typical client regarding the value of accurate PCS estimates indicated that only "trivial savings" are possible, and demonstrates that the project development process is inherently focused on cost savings. If true, the apparent impact is an institutional bias to minimize project cost, i.e., deliver as cheaply as possible. Combining the finding of Crosset and Hines (2007) that 82\% of projects over 5.0 million USD overrun their budgets with the collective findings cited above that design deficiencies generate the majority of post-award construction cost growth leads to the inevitable conclusion that focusing on cost savings during preconstruction has not been successful and may even exacerbate the cost growth by unintentionally capping the resources available to produce construction documents that are free of defects. Therefore, a paradigm shift in the CEM culture is in order to replace the overarching preconstruction decision criterion from "minimize cost" to "maximize cost certainty." This paper proposes that PCS costs be viewed as an investment in the preconstruction planning, design, and procurement process. If the preconstruction process is adequately funded, the return on that investment can be measured in terms of enhanced cost certainty through the production of highquality construction and tender documents.

A simple example can be found in highway pavement projects. The use of asphalt pavement is normally considered to cost less than Portland cement concrete pavement. However, the price of liquid asphalt is considerably more volatile than that of Portland cement (Tighe, 2001). Thus, deciding to use concrete pavement for a road that is starting its project development process and will take several years to reach the point where the tender can be advertised can be seen as increasing the certainty that the construction materials will be available at or below the pricing assumed in the initial programming-level cost estimate. A recent study of alternative pavement bidding in the US actually tested this concept (Gransberg et al., 2017). When both pavement types were competed head-to-head with no life cycle cost adjustment, the prices for both pavement types decreased owing to the increased competition and concrete won $67 \%$ of the time. Thus, the lesson learned in this example is that by spending an additional incremental amount to develop the construction documents for two rather than one pavement type, the client reduced the material price volatility risk. In the words of one typical client: "Bidding pavements 'head-to-head' allows the open market to determine what is constructed not outdated assumptions made during the evaluation/selection process years before letting" (Lenz, 2010).

\subsection{Cost certainty case study}

A study funded by the Oklahoma Turnpike Authority (Gransberg et al., 2007) found a correlation between consultant's design fees (expressed as a percentage of estimated construction cost at the time the fee was established) and construction cost growth from that early estimate. Data was gathered on 31 projects for the period 1998 through 2003, which constituted that client's entire construction program for five years. All projects were awarded on an LTO basis after advancing the design to $100 \%$. Figure 1 shows the result for the linear regression analysis on the population. It shows that, up to a point, spending more on the design fee creates the ability to 


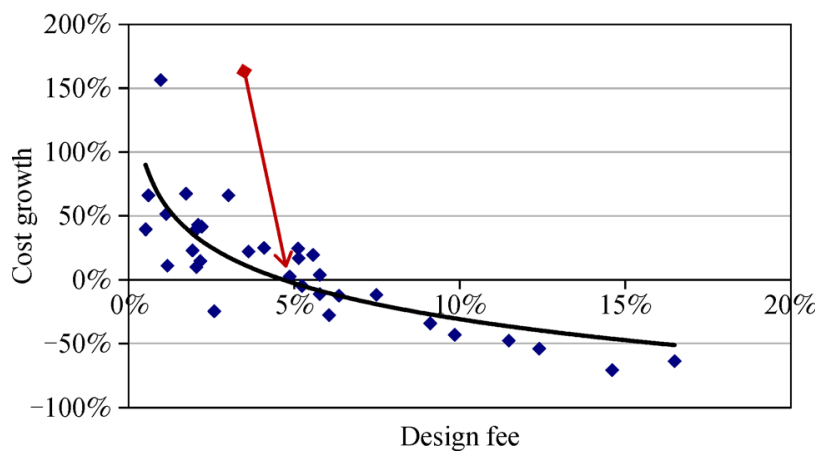

Fig. 1 Cost growth from initial estimate vs. design fee of total OTA population. Reprinted from (Gransberg et al., 2007) with permission from ASCE. The arrow shows the point where the initial estimate is reduced during preconstruction

increase the certainty that the project will be completed at or below its early estimate. This occurred at around 5\% in the Oklahoma sample. Coincidentally, the turnpike authority's policy was to budget $3 \%$ to $5 \%$ for preconstruction (Oklahoma Turnpike Authority (OTA), 1999).

Figure 1 includes all projects regardless of technical complexity. The line is the best fit $(\mathrm{R} 2=0.63)$. Intuitively, a client would expect to pay more for the design of a complex bridge project than it would for an asphalt overlay. Thus, it is important to split the population to validate this assumption. Figure 2 shows the results of regressing only the bridge projects. The figure not only confirms that the assumption is correct, but also confirms the trend with regard to the benefits accrued during construction as a result of increasing the investment in the preconstruction process. The high coefficient of determination $(\mathrm{R} 2=0.93)$ testifies to the potential for increasing construction cost certainty by increased the investment in the cost of preconstruction.

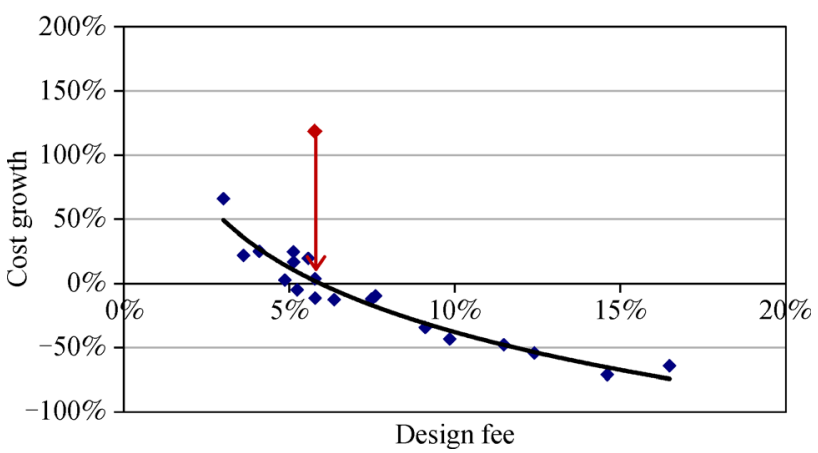

Fig. 2 Cost growth from initial estimate vs. design fee of bridge projects from OTA population . Reprinted from (Gransberg et al., 2007) with permission from ASCE. The arrow shows the point where the initial estimate is reduced during preconstruction of bridge projects

\subsection{Impact on the CEM culture}

Given the above discussion, the shift in paradigm away from LTO toward BV must have a pronounced impact on the CEM culture itself. The old culture is one where both design engineers and contractors are rewarded for delivering the cheapest possible product (Tran et al., 2016). One only has to look at the amount of time a structural engineer spends working to reduce the amount of reinforcing steel in a concrete beam to see how deeply ingrained the "cheapest is best" mentality runs. Similarly, research has shown that construction contractors fundamentally disbelieve that a project can be won by other than the lowest price (Lopez del Puerto et al., 2008). A critical analysis of over 100 public BV solicitations (Gransberg and Barton, 2007) found that nearly $90 \%$ still used an award metric that gave more than $50 \%$ of the weight to the lowest price, which led the authors to conclude that "even when the owner desires to include factors other than low price, they defeat their efforts by applying heavy weighting to price essentially turning the procurement into one where only the low bidder can win." Therefore, the real challenge to the CEM culture is one of rooting out the inherent bias that believes that value can only be measured in financial terms, and replacing it with one that truly recognizes that VfM can be realized in non-monetary terms such as increasing cost and schedule certainty or enhancing quality to increase the certainty of actual project service lives.

\section{Conclusions and recommendations}

After describing the LTO and BV award procedures, it was found that these still use the lowest cost metric, albeit in a disguised form. In $\mathrm{BV}$, the attributes are still weighed against cost, and there is still the burden of proving that the client's final cost will be lower (ultimately). The authors of this paper believe that the output of the above-described analysis makes a compelling argument that CEM culture should refocus its efforts on enhancing project cost certainty rather than merely searching for means to accrue cost savings. The difference in the two approaches is subtle but extremely important. To make the transition, engineering management tools must be advanced to the next level. This means that all project control tools for managing cost, schedule, and technical scope must be transformed from working in deterministic mode to the stochastic mode, thus making the probability of completing the project at or below its official budget the primary decision criterion. To do so, CEMs must accept that there is a benefit in paying more for an alternative that increases the cost certainty for the entire project.

The authors of this paper hope that it will provide the grist for a more general dialog across all industry sectors where engineering management is practiced. Obviously, the details described above are only applicable to CEM in 
the transportation sector in North America. However, the paper's fundamental theoretical construct is valid across all sectors. Moving from managing technical projects deterministically to minimize their costs, to managing the same projects stochastically, will have different levels of benefit in different market sectors. The philosophy of holding engineering managers accountable for finishing projects of all types according to the prework plan, budget, and schedule by measuring performance in terms of outcomes applies to all sectors. Now, hopefully, the dialog will begin.

\section{References}

Arditi D, Akan G T, Gurdamar S (1985). Cost overruns in public projects. International Journal of Project Management, 3(4): 218-224

Alavi S, Tavares M P (2009). Highway Project Cost Estimating and Management. Technical Report FHWA/MT-08-007/8189

Bamberger C, Stark M (2008). Best practices for use of best value selections AGC of America \& NASFA. https://www.agc.org/sites/ default/files/Project_Delivery-_Best_Value_Selection.pdf, 2017-111

Beard L J, Loulakis C M, Wundram C E (2001). Design-Build: Planning through Development. New York: McGraw-Hill Professional

Beemer J (2005). The cost of perfection in public works projects: A design professional's perspective. American Council of Engineering Companies, Government Advocacy, http://www.acec.org/advocacy/ pdf/ tcop_2006-04-20.pdf, 2017-1-11

Blanchard B (2007). Design-build lessons learned Florida DOT. In: Proceedings of Louisiana Transportation Engineering Conference. Baton Rouge, 6-14

Botha P S, Scheepbouwer E (2015). Christchurch rebuild, New Zealand: Alliancing with a difference. Proceedings of the Institution of Civil Engineers-Management, Procurement and Law, 168(3): 121-129

Bubshait A A, Al-Said F A, Abolnour M M (1998). Design fee versus design deficiency. Journal of Architectural Engineering, 4(2): 44-46

Burati J L Jr, Farrington J J, Ledbetter W B (1992). Causes of quality deviations in design and construction. Journal of Construction Engineering and Management, 118(1): 34-49

Carr P G, Beyor P S (2005). Design fees, the state of the profession, and a time for corrective action. Journal of Management Engineering, 21 (3): 110-117

CBC News (2015). Charbonneau commission report: A deeper look at the recommendations. http://www.cbc.ca/news/canada/montreal/ charbonneau-commission-report-recommendations-1.3335460, 2017-1-11

Charbonneau F, Lachance R (2015). Final Report of the Commission of Inquiry on the Awarding and management of contracts public in the construction industry. https://www.ceic.gouv.qc.ca/fileadmin/ Fichiers_client/fichiers/Rapport_final/Rapport_final_CEIC_Integral_c.pdf (in French)

Craigie E K, Gransberg D D, Jeong H D (2016). Cost and scope breakdown structure for functional level estimating of consultant fees. Transportation Research Record: Journal of the Transportation Research Board, 2573: 157-163

Crosset J, Hines L (2007). Comparing State DOTs' Construction Project
Cost and Schedule Performance: 28 Best Practices from Nine States. AASHTO, Washington

Crowley L G, Hancher D E (1995). Evaluation of competitive bids. Journal of Construction Engineering and Management, 121(2): 238245

Curry B (2016). Competition Bureau warns of bid-rigging as Ottawa set to spend on infrastructure. http://www.theglobeandmail.com/, 201605-29

Ellis R D, Herbsman Z, Kumar A (1991). Evaluation of the FDOT design/build program. Final Report, Submitted to Florida Deptment of Transportation, State Project No. 99700-7543-010, Department of Civil Engineering, University of Florida, Gainesville

Federal Highway Administration (FHWA) (2006). Design-build effectiveness study. http://www.fhwa.dot.gov/reports/designbuild/designbuild0.htm, 2016-05-29

Girard D (2016). Charbonneau Commission Follow-up: Ethics Lessons for Quebec and Elsewhere. Webinar Presentation, http://epac-apec. ca/wp-content/uploads/2014/11/charbonneau-webinar-april-2016final.pdf

Gransberg D D, Barton R F (2007). Analysis of federal design-build request for proposals evaluation criteria. Journal of Management Engineering, 23(2): 105-111

Gransberg D D, Buss A, Karaca I, Loulakis M C (2017). Alternate design/Alternate bid process for pavement type selection. NCHRP Synthesis Report 20-05/Topic47-02

Gransberg D D, Ellicott M A (1997). Best value contracting criteria. Cost Engineering, 39(6): 31-34

Gransberg D D, Jeong H D, Lopez del Puerto C, Hunter K D (2014). Preconstruction Services Estimating Guidebook. Interim Research Report, NCHRP Project 15-51

Gransberg D D, Lopez del Puerto C, Humphrey D (2007). Relating cost growth from the initial estimate to design fee for transportation projects. Journal of Construction Engineering and Management, 133 (6): 404-408

Gransberg D D, Molenaar K R (2008). Does design-build project delivery affect the future of the public engineer? Transportation Research Record: Journal of the Transportation Research Board, 2081: 3-8

Harp D W (1991). Historical background-Low bid concept. Transportation Research Circular, 386: 43-47

Higbee J B (2004). Geotechnical issues with large design-Build highway projects. Transportation Research Record: Journal of the Transportation Research Board, 1868: 147-153

Hoke T (2012). A question of ethics: The ethical aspects of competition. Civil Engineering Magazine Archive, 82(10): 44-45

Hunter K D, Gransberg D D (2014). Comparative analysis of two models for estimating highway project design costs. Transportation Research Board Annual Meeting 2014, National Academies, Compendium, Paper 14-3967

Janacek J (2006). Construction costs going through the roof? 2006 Public Works Officer Institute, Presentation, Los Angeles

Kirby J G, Furry D A, Hicks D K (1988). Improvements in design review management. Journal of Construction Engineering and Management, 114(1): 69-82

Kraft E, Park H, Gransberg D D (2014). Performance bond: Cost benefit, and paradox for public highway agencies. Transportation Research 
Record: Journal of the Transportation Research Board, 2408: 3-9

Lenz R (2010). TxDOT's alternate pavement design and bid policy. Texas Asphalt Paving Association Annual Meeting, Presentation, Austin

Lopez del Puerto C, Craigie E, Gransberg D D (2016). Construction cost certainty versus construction savings: Which is the correct approach? In: Proceedings of Transportation Research Board 95th Annual Meeting. Washington, 16-2754

Lopez del Puerto C, Gransberg D D, Shane J S (2008). Comparative analysis of owner goals for design/build projects. Journal of Management Engineering, 24(1): 32-29

Mendez V (2010). Every day counts: Innovation initiative. Federal Highway Administration, Washington

Minchin R E, Chini A P (2016). Alternative Contracting Research. Final Research Report, FDOT Contract Number BDV31-977-40, Florida DOT, Tallahassee

Molenaar K R, Gransberg D D (2001). Design-builder selection for small highway projects. Journal of Management Engineering, 17(4): 214 223

Morgen E T (1986). Claims by the federal government against its A/ E-Guidelines for improving practice. Office for Professional Liability, Research of Victor O. Schinner, Washington

Odeck J (2004). Cost overruns in road construction-What are their sizes and determinants? Transport Policy, 11(1): 43-53

Oklahoma Turnpike Authority (OTA) (1999). Standards and Specifications, Oklahoma City

Rueda-Benavides J A, Gransberg D D (2014). Indefinite delivery/ indefinite quantity contracting: A case study analysis. Transportation Research Record, 2408: 17-25

Scheepbouwer E, Humphries A B (2011). Transition in adopting project delivery method with early contractor involvement. Transportation Research Record, 2228: 44-50
Scott S, Molenaar K R, Gransberg D D, Smith N C (2006). Best Value Procurement for Highway Construction Projects. NCHRP Report Project 10-61

Shane J S, Gransberg D D, Molenaar K R, Gladke J R (2006). Legal challenge to a best-value procurement system. Leadership and Management in Engineering, 6(1): 20-25

Songer A D, Ibbs C W, Napier T R (1994). Process model for public sector design-build planning. Journal of Construction Engineering and Management, 120(4): 857-874

Szeliga K R (2005). Conflict and intrigue in government contracts: A guide to identifying and mitigating organizational conflicts of interest. Public Contract Law Journal, 35(4): 639-674

Tighe S (2001). Guidelines for probabilistic pavement life cycle cost analysis. Transportation Research Record, 1769: 28-38

Tran D, Molenaar K R, Gransberg D D (2016). Implementing best-value procurement for design-bid-build highway projects. Transportation Research Record: Journal of the Transportation Research Board, 2573: $26-33$

Van de Rijt J, Santema S (2012). The best value approach in the Netherlands: A reflection on past, present and future. Journal for the Advancement of Performance Information and Value, 4(2): 147-160

West N, Gransberg D D, McMinimee J (2012). Effective tools for projects delivered using the construction manager/general contractor method. Transportation Research Record, 2268: 33-39

Yu W, Wang K (2012). Best value or lowest bid? A quantitative perspective. Journal of Construction Engineering and Management, 138(1): 128-134

Yuan J, Zeng A, Skibniewski M J, Li Q (2009). Selection of performance objectives and key performance indicators in publicprivate partnership projects to achieve value for money. Construction Management and Economics, 27(3): 253-270 